9 Egypt

$10{ }^{3}$ Department of Biochemistry, Modern University for Technology and Information (MTI), PO

11 11566, Cairo, Egypt

$12{ }^{4}$ Department of Cardiology, Faculty of Medicine, Ain Shams University (ASU), PO 11566,

13 Cairo, Egypt

14 5epartment of Microbiology \& Immunology, Faculty of Pharmacy, Ain Shams University 15 (ASU), PO 11566, Cairo, Egypt

17 *Corresponding Author: Khaled M. Aboshanab (PhD)

18 Address: Department of Microbiology and Immunology, Faculty of Pharmacy, Ain Shams 19 University, organization of African unity St. PO: 11566, Abbassia, Cairo, Egypt.

20 E-mail:aboshanab2012@pharma.asu.edu.eg

21 Tel: (202)25082595

22 Mobile: (002)01007582620

23 Fax: (202)24051107

24

25

26

\section{Conflict of interest}

28 The authors declare that they have no conflict of interest 


\section{Abstract}

Aim: Infective endocarditis (IE) is a major complication of Staphylococcus (S.) aureus infection in humans particularly those with bacteremia. Although Staphylococcus species are commensal on or in different parts of the human body, it is also known to be a serious pathogen causing bacteremia and sepsis that could lead to IE. Therefore, our aim was to assess the prevalence as well as phenotypic and genotypic association of the Staphylococcal superantigens (SAgs) among bacteremic and IE patients.

Methods: This study was conducted on Staphylococcus isolates recovered from bacteremic and

IE patients. The isolates were screened phenotypically for the detection of SAgs including detection and analysis of sea, seb, sec, sed, see and tsst-1, the major SAgs coding genes were performed using PCR and agarose gel electrophoresis, respectively. The obtained findings were

42 statistically analyzed using standard methods.

Results: Detection of SAgs using ELISA revealed that $12(46 \%)$ isolates were positive for enterotoxin production. However, the PCR revealed that 19 (73\%) isolates were positive for enterotoxin genes with the highest prevalence of the sea gene (79\%), followed by the seb $(63 \%)$, tsst-1 (21\%). The least frequent gene was the sed (5.3\%). Accordingly, phenotypic and genotypic

47 screening for prevalence of SAgs among Staphylococcal isolates showed significant difference $(P$ value $=0.046703)$, however, no significant correlation could be observed among the coagulase

49 negative Staphylococci (CoNS) isolates $(P$ value $=0.248213)$. Statistical correlations between bacteremic and IE isolates with respect to prevalence of SAgs, showed no significant difference

$51 \quad(P$-value $=0.139$, Effect size $=0.572)$ indicating no specific association between any of the 52 detected SAgs and IE. 
53 Conclusion: no significant difference has been found between Staphylococcal IE and bacteremia

54 isolates regarding both phenotypic and genotypic detection of the most commonly SAgs.

55 Therefore, all Staphylococcal bacteremic patients are suspected for IE. Also, future work should

56 be conducted for analysis of SAgs gene expression.

57 Key words: Bacteremia; Infective endocarditis; Staphylococcus species; Superantigens

\section{Introduction}

S. aureus is a dangerous and versatile human pathogen because of its ability to cause various types of infections, including skin and soft tissue sepsis, pneumonia, bloodstream infections

62 (BSIs), osteomyelitis and infective endocarditis (IE) [1]. Higher mortality rate (15-25\%) was recently reported from serious $S$. aureus infections, particularly bacteremia and endocarditis $[2,3]$. IE is a major devastating complications of Staphylococcal bacteremia [3,4]. In 2018, Asgeirsson et al. reported that $S$. aureus is the foremost cause of IE where it comprises about 15$40 \%$ of all IE cases worldwide [3].

67 IE is caused principally with bacteria or fungi where serious clinically relevant complications including, damaging of one or more of the heart valves, necrosis of mural endocardium, or

69 sometimes septal defects could occur [5]. Moreover, IE is distinguished by the development of

70 “cauliflower- like" vegetations, consisted of host factors including, fibrin, platelets and bacterial

71 aggregates on the damaged endothelium of heart valves [6,7]. Host related risk factors for IE

72 have been established. Patient groups at high risk of developing $S$. aureus bacteremia include

73 patients with high rates of colonization, immunosuppressive conditions such as cancer, diabetic

74 patients as well as patients on hemodialysis. Insertion of foreign bodies such as central and

75 peripheral venous catheters, prosthetic heart valves and joints increases the risk of infection 
$76[8,9]$. However, the involvement of bacterial complications still needs further studies to be

77 identified, as the basis of staphylococcal virulence and switching between commensal and

78 pathogenic phenotypes is still obscure.

79 Based on the European viewpoint, clinical picture, microbiological analysis and 80 echocardiographic investigations are the most helpful techniques that are usually used for

81 diagnosis of IE [10]. The widely accepted Duke criteria provide high sensitivity and specificity

82 for the diagnosis of IE where series of major and minor clinical and pathologic criteria are 83 implemented $[11,12]$.

84 SAgs are significant virulence factors that contributed to variety of pathological conditions, 85 including, pneumonia, soft tissue sepsis, toxic shock syndrome, and IE. They have been found to play a very critical part in the pathogenesis of IE [6,7]. IT was recently reported in 2020 , that

87 Sags particularly the $S$. aureus enterotoxins play important role in the induction of asthma of 88 hospitalized patients by inducing IgE production [13]. S. aureus strains secrete up to 23 of at least 24 serologically distinct SAgs including TSST-1, SEs and the SE-like (SE-1) $[8,14,15]$.

90 These SAgs have the distinctive capability to concurrently bind both major histocompatability complex and the T-cell receptor, exerting immune response $20 \%$ greater than that of ordinary

92 antigens $[16,17]$. This immune response is associated with a substantial discharge of various inflammatory cytokines and several interleukins which could have a direct cytotoxic effect on the endothelial cells [7]. Because of the presences of the adhesion surface molecules located on

95 the S. aureus, it becomes able to adhere to the cardiac endothelial cells and direct release the cytokines and therefore, the inflammation of the cardiac muscles are initiated causing IE [18].

97 Despite of the advancements in the field of therapies and infection control, both the morbidity 
99 becomes worse up on the emergence of multidrug resistant strains such as methicillin-resistant $S$.

100 aureus (MRSA) [2,19].

101 According to literature, the prevalence of SAgs and their production among Staphylococcus

102 clinical isolates associated with IE, particularly in Egypt, has not been well-defined. For that 103 reason we assessed the prevalence of the Staphylococcal SAgs and their association among 104 bacteremic and IE patients.

\section{Methods}

\section{Clinical specimens and patient data}

107 Blood specimens were collected from 88 bacteremic patients. The blood specimens were 108 submitted to the Microbiology Laboratory, El-Demerdash hospital Ain Shams University and Ain Shams University Specialized hospital, Cairo, Egypt, for routine culture. Specimens were collected during the period from November 2015 to February 2017. A total of 84 (95.5\%) blood

111 specimens showed positive blood culture, of these, $18(21.4 \%)$ specimens were collected from

112 patients diagnosed by the cardiologist to have infective endocarditis based on the Modified Duke 113 criteria [20-22]. Blood specimens were collected from patients having fever and preferably on 114 early admission. Patients without fever or those who have been admitted to the hospital for more 115 than one week have been excluded from our study. The whole study was approved by the 116 Faculty of Pharmacy, Ain Shams University Research Ethics Committee (ENREC-ASU-Nr. 65)

117 where both informed and written consent were obtained from patients or parents of patients after 118 explaining the study purpose. 


\section{Identification and antimicrobial susceptibility testing for the Staphylococcus isolates}

Identification of Gram positive and Gram negative isolates was performed according to Bergy's Manual [23]. All Staphylococcal isolates were subjected to susceptibility testing against vancomycin $(30 \mu \mathrm{g})$; clindamycin $(2 \mu \mathrm{g})$; gentamicin $(10 \mu \mathrm{g})$ and ciprofloxacin $(5 \mu \mathrm{g})$ using modified Kirby Bauer disc diffusion method as recommended by CLSI 2016 guidelines [24]. Phenotypically, MRSA isolates were identified by their resistance to cefoxitin disc $(30 \mu \mathrm{g})$ as recommended by the CLSI, 2016 [24]. S. aureus ATCC $^{\circledR} 25923$ standard strain was used for the quality control of antimicrobial susceptibility tests

\section{Phenotypic detection of Staphylococcal enterotoxins using ELISA}

The presence of SEs A, B, C, D and E in bacterial supernatants was assessed using VIDAS ${ }^{\circledR}$ Staph enterotoxin II kit (BioMerieux, France), following the manufacturer's protocol. A result with a test value that is less than the threshold value $(<0.13)$ indicated that the sample either does not contain $\mathrm{SE}$ or the toxin concentration was below the detection limit. On the other side, a result with a test value that is $\geq 0.13$ indicated the presence of any type of the enterotoxins.

\section{Molecular analysis of Staphylococcal SAgs}

Genomic DNA purification was carried out using Thermo Scientific GeneJET Genomic DNA Purification Kit (Thermo Scientific, UK), following the manufacturers protocol. As shown in table 1, six pairs of primer were used for the PCR amplification of the SAg genes including, sea, seb, sec, sed, see and tsst genes, coded for SEs A, B, C1, D, E and TSST-1, respectively.[25]. Each PCR reaction contained $12.5 \mu \mathrm{l}$ of DreamTaq Green PCR Master Mix (2X), 100 pmol/ $\mu 1$ of each primer for each gene, 100 nmole of chromosomal DNA and continue up to $25 \mu$ with sterile nuclease-free water. DNA Amplification was performed using a Horizontal Thermocycler (Biometra, Germany), with the following thermal cycling profile: initial denaturation step at 94 
142

143

144

145

146

147

148

149

150

151

152 level of 0.05 was used. [26]

${ }^{\circ} \mathrm{C}$ for 5 min, followed by 35 cycles of denaturation at $95^{\circ} \mathrm{C}$ for $2 \mathrm{~min}$, annealing at $50^{\circ} \mathrm{C}$ for 2 min, extension at $72^{\circ} \mathrm{C}$ for $1 \mathrm{~min}$, followed by final extension at $72^{\circ} \mathrm{C}$ for $7 \mathrm{~min}$. The PCR products was analyzed using $0.8 \%$ agarose gel electrophoresis and verified by DNA sequencing

Table 1. Primer sequences and expected sizes of PCR products

\begin{tabular}{|c|c|c|c|c|}
\hline Gene & Primer sequence $\left(5^{\prime}-3^{\prime}\right)$ & $\begin{array}{l}\text { Expected } \\
\text { size (bp) }\end{array}$ & $\mathbf{T a}$ & Reference \\
\hline $\begin{array}{l}\text { Sea (Staphylococcal type } \\
\text { A enterotoxin) }\end{array}$ & $\begin{array}{l}\text { F-GGTTATCAATGTGCGGGTGG } \\
\text { R-CGGCACTTTTTTCTCTTCGG }\end{array}$ & 102 & 50 & {$[24]$} \\
\hline $\begin{array}{c}\text { Seb (Staphylococcal type } \\
\text { B enterotoxin) }\end{array}$ & $\begin{array}{l}\text { F-GTATGGTGGTGTAACTGAGC } \\
\text { R-CCAAATAGTGACGAGTTAGG }\end{array}$ & 164 & 50 & {$[24]$} \\
\hline $\begin{array}{l}\text { Sec (Staphylococcal type } \\
\text { C1 enterotoxin) }\end{array}$ & $\begin{array}{l}\text { F-AGATGAAGTAGTTGATGTGTATGG } \\
\text { R-CACACTTTTAGAATCAACCG }\end{array}$ & 451 & 50 & {$[24]$} \\
\hline $\begin{array}{l}\text { Sed (Staphylococcal type } \\
\text { D enterotoxin) }\end{array}$ & $\begin{array}{l}\text { F-CCAATAATAGGAGAAAATAAAAG } \\
\text { R-ATTGGTATTTTTTTCGTTC }\end{array}$ & 278 & 50 & {$[24]$} \\
\hline $\begin{array}{l}\text { See (Staphylococcal type } \\
\text { E enterotoxin) }\end{array}$ & $\begin{array}{l}\text { F-AGGTTTTTTCACAGGTCATCC } \\
\text { R-CTTTTTTTTTCTTCGGTCAATC }\end{array}$ & 209 & 50 & {$[24]$} \\
\hline $\begin{array}{l}\text { tsst- } 1 \text { (Toxic shock } \\
\text { syndrome toxin-1) }\end{array}$ & $\begin{array}{l}\text { F-ACCCCTGTTCCCTTATCATC } \\
\text { R-TTTTCAGTATTTGTAACGCC }\end{array}$ & 326 & 50 & {$[24]$} \\
\hline
\end{tabular}

\section{Results}

\section{Study population}

155 The study was conducted on 84 positive culture male $(65 ; 77.3 \%)$ and $19(22.6 \%)$ female

156 bacteremic patients. Based on the Modified Duke criteria, 18/84 (21.4\%) patients were

157 diagnosed by the cardiologist with IE. A summary of these 18 patient's demographics and

158 clinical characteristics are presented in table 2. The eighteen patients showed native valve 
159 endocarditis. There were $14(77.7 \%)$ patients having damage in one single valve, while 4

$160(22.2 \%)$ patients had defects in two valves. Among these patients, the tricuspid valve was the

161 most commonly affected $(9 ; 50 \%)$ followed by the mitral $(8 ; 44.4 \%)$ and then aortic $(5 ; 27.7 \%)$.

162 Table 2. Demographics and clinical characteristics of 18 patients with IE

\begin{tabular}{|c|c|c|}
\hline Variable & Number & $\begin{array}{l}\text { Percentage } \\
(\%)\end{array}$ \\
\hline \multicolumn{3}{|l|}{ Gender } \\
\hline Male & 15 & $83 \%$ \\
\hline Female & 3 & $17 \%$ \\
\hline \multicolumn{3}{|l|}{ Valve type } \\
\hline i)-native & 18 & $100 \%$ \\
\hline a) Tricuspid (T) & 9 & $50.0 \%$ \\
\hline b) $\operatorname{Mitral}(\mathrm{M})$ & 8 & $44.5 \%$ \\
\hline c) $\operatorname{Aortic}(\mathrm{A})$ & 5 & $27.7 \%$ \\
\hline ii)-prosthetic & 0 & $0 \%$ \\
\hline \multicolumn{3}{|l|}{ Number of Valve affected } \\
\hline a) Single valve & \multicolumn{2}{|c|}{$14(77.7 \%)$} \\
\hline b) Two valves & \multicolumn{2}{|c|}{$\begin{array}{c}4(22,2 \%): \\
\mathrm{T}+\mathrm{M}(3 ; 75 \%) \\
\mathrm{T}+\mathrm{A}(1 ; 25 \%)\end{array}$} \\
\hline Age (years) & \multicolumn{2}{|c|}{$17-48$} \\
\hline \multicolumn{3}{|l|}{ Smoker } \\
\hline Yes & 14 & $78 \%$ \\
\hline No & 4 & $22 \%$ \\
\hline \multicolumn{3}{|l|}{ Addiction } \\
\hline Injection drug users (IDUs). & 12 & $66.6 \%$ \\
\hline \multicolumn{3}{|l|}{ Hepatitis C virus (HCV) } \\
\hline Yes & 10 & $56 \%$ \\
\hline No & 8 & $44 \%$ \\
\hline \multicolumn{3}{|l|}{ Surgery performed } \\
\hline Yes & 4 & $22 \%$ \\
\hline No & 14 & $78 \%$ \\
\hline \multicolumn{3}{|l|}{ Admitted to ICU } \\
\hline Yes & 2 & $11 \%$ \\
\hline No & 16 & $89 \%$ \\
\hline \multicolumn{3}{|l|}{ Comorbidities } \\
\hline On hemodialysis & 1 & $5.5 \%$ \\
\hline Diabetes & - & $0 \%$ \\
\hline Cancer & 1 & $5.5 \%$ \\
\hline No comorbidities & 16 & $89 \%$ \\
\hline \multicolumn{3}{|l|}{ Complications } \\
\hline Renal failure & 1 & $5.5 \%$ \\
\hline Pneumonia/ lung abscess & 2 & $11 \%$ \\
\hline Peripheral septic emboli & 1 & $5.5 \%$ \\
\hline No complications & 14 & $78 \%$ \\
\hline
\end{tabular}




\subsection{Microbial Population and antimicrobial sensitivity}

165

166

167

168

169

170

171

172

173

174

175

176

177

178

Laboratory examination of 84 positive culture specimens, a total of 85 clinical isolates (83 specimens gave single and 1 specimen was double culture) were recovered, of these, 59 (69.4\%), 22 (25.8\%) and 4 (4.7\%) were Gram positive, Gram negative and Candida spp., respectively. Among the Gram positive isolates, the most common organisms identified were the CoNS (30; $50.8 \%)$, followed by $S$. aureus $(26 ; 44.1 \%)$ and Streptococcus spp. $(3 ; 5.1 \%)$. The most common CoNS isolated were $S$. epidermidis representing $50 \%$, followed by the S. lugdunensis, $S$. haemolyticus and S. intermedius representing $23.3 \%, 20 \%$ and $6.6 \%$, respectively.

As shown in table 3; among the $S$. aureus isolates, $24(92.3 \%)$ were MRSA. Moreover, the sensitivity of $S$. aureus isolates against vancomycin, clindamycin, ciprofloxacin and gentamicin were $92.3 \%, 65.4 \%, 61.5 \%$ and $50 \%$, respectively. On the other hand, the sensitivity of CoNS against vancomycin, ciprofloxacin and gentamicin clindamycin and cefoxitin, were 93.3\%, 40\%, $36.6 \%, 33.3 \%$, and $6.6 \%$, respectively.

Table 3. Antimicrobial susceptibility pattern of the recovered Staphylococci

\begin{tabular}{lcccccc}
\hline & \multicolumn{5}{c}{ Susceptibility pattern of Staphylococci isolates } \\
\cline { 2 - 6 } Antimicrobial & \multicolumn{3}{c}{ S. aureus $(\mathbf{N}=\mathbf{2 6})$} & \multicolumn{3}{c}{ CoNS (N=30) } \\
\cline { 2 - 6 } \multicolumn{1}{c}{ agent } & Sensitive & Intermediate & Resistant & Sensitive & Intermediate & Resistant \\
& No. (\%) & No. (\%) & No. (\%) & No. (\%) & No. (\%) & No. (\%) \\
Vancomycin & $24(92.3)$ & 0 & $2(7.7)$ & $28(93.3)$ & 0 & $2(6.7)$ \\
Clindamycin & $17(65.4)$ & 0 & $9(34.6)$ & $10(33.3)$ & $2(6.6)$ & $18(60)$ \\
Gentamicin & $13(50.0)$ & $1(4)$ & $12(46)$ & $11(36.6)$ & $2(6.6)$ & $17(56.6)$ \\
Cefoxitin & $2(7.7)$ & 0 & $24(92.3)$ & $2(6.6)$ & 0 & $28(93.3)$ \\
Ciprofloxacin & $16(61.5)$ & 0 & $10(38.4)$ & $12(40)$ & $3(10)$ & $15(50)$ \\
\hline
\end{tabular}




\section{Microbiology of the IE Cases}

183

184

185

186

187

188

189

190

191

192

193

Out of the 18 blood specimens collected from IE patients, 19 microbial isolates were recovered.

The most common pathogen was $S$. aureus (10;52.6\%), followed by CoNS representing (5; 26.3\%), Gram negative isolates represented $(3 ; 15.7 \%)$ while one isolate was from the Candida spp. $(5 \%)$.

\section{Phenotypic SAg detection}

Twenty six Staphylococcal isolates were selected (15 isolates recovered from IE patients and 11 isolates from bacteremic patients), for the detection of SAgs using ELISA. Only, 12 isolates (46\%) were positive SAg production while the remaining 14 isolates (54\%) were negative. The 12 positive SAg isolates were, 9 (75\%) from IE and $3(25 \%)$ from bacteremic patients without IE. The mean for the ELISA score was 0.995 and the median was 0.05 . The P50 was 0.05, which indicated that $50 \%$ of the tested isolates showed an ELISA score less than 0.05 . The value of P75 was 2.04 which indicated that $75 \%$ of the isolates showed an ELISA score less than 2.04, while the P90 was 2.108 which means than $90 \%$ of the isolates revealed a score less than 2.108 .

\section{Molecular analysis of Staphylococcal SAgs}

As shown in table 4, out of the 26 isolates, 19 (73\%) harbored at least one SAg gene, of these, 8 isolates were positive for only one and 11 were positive for two or more genes. Out of the 19 positive isolates, $14(73.7 \%)$ and $5(26.3 \%)$ were from IE and bacteremic patients without IE, respectively. The most frequent gene found among the tested isolates was sea gene representing $79 \%$ of the isolates, followed by the seb and the tsst-1 genes representing $63 \%$ and $21 \%$, respectively. The least frequent gene was the sed representing only 5.3\%. However, sec and see genes were absent in any of the tested isolates. There was a statistically significant difference in the overall prevalence of the sea gene compared to the other genes detected among the tested 
205 isolates $(p=0.001)$. To contrast differences between $S$. aureus and CoNS genetic profile, among

206 S. aureus isolates, sea gene was the most prominent gene and was identified in $65 \%$ of the 207 studied S. aureus isolates, however it was only identified in 33.3\% of CoNS. On the other hand, 208 seb, tsst and sed genes were present in 50\%, 20\% and $5 \%$ of $S$. aureus isolates, respectively.

209 Though, among CoNS, seb and sed genes were both present each in $33.3 \%$, while the sed gene 210 was not detected in any of the tested isolates.

211 Table 4. Distribution of SAg genes among Staphylococci

\begin{tabular}{|c|c|c|}
\hline Genes & \multicolumn{2}{|c|}{$\begin{array}{l}\text { No. (\%) of Staphylococcal isolates harbored SAg genes } \\
\qquad(\mathrm{N}=\mathbf{2 6})\end{array}$} \\
\hline Detection of gene(s) & Positive: 19 (73\%) & $\begin{array}{l}\text { EI patients } 14(73.7 \%) \\
\text { Bacteremic patients } \\
\text { without IE, } 5(26.3 \%)\end{array}$ \\
\hline & Negative: 7 (27\%) & \\
\hline $\begin{array}{l}\text { One SAg } \\
\geq 2 \text { SAg }\end{array}$ & $\begin{array}{c}8(42 \%) \\
11(57.9 \%)\end{array}$ & $P$-value $=0.491$ \\
\hline Types of genes detected & & \\
\hline sea & $15(79 \%)$ & \\
\hline seb & $12(63 \%)$ & \\
\hline $\sec$ & $0(0 \%)$ & \\
\hline sed & $1(5.3 \%)$ & $P-$ value $=0.001$ \\
\hline see & $0(0 \%)$ & \\
\hline tsst-1 & $4(21 \%)$ & \\
\hline
\end{tabular}

214 We studied the statistical correlations between IE and bacteremic isolates with respect to 215 the phenotypic and genotypic detection of SAg. Mann-Whitney Rank Sum Test and 216 Fisher's Exact test were performed to test for the significance of the SAg as detected 217 phenotypically using ELISA test and genotypically using PCR amplification among 218 bacteremic and IE Staphylococcus isolates. As shown in table 5, no significant 219 difference has been found when comparing the results of the ELISA test among IE and 220 bacteremic isolates $(P$-value $=0.085$, Effect size $=0.677)$. There was no statistically 
221 significant difference between prevalence of sea, seb, sed and tsst-1 genes among

222 bacteremic and IE patients $(P$ value $=0.426$, Effect size $=0.212),(P$ value $=0.453$,

223 Effect size $=0.168),(P$ value $=0.423$, Effect size $=0.234)$ and $(P$-value $=0.113$, Effect

224 size $=0.365)$, respectively. There was also no statistically significant difference has

225 been found between the total number of SAg genes present among IE and bacteremic

226 Staphylococcal isolates $(P$-value $=0.139$, Effect size $=0.572)$. Statistical analysis

227 indicated significant difference in the genotypic detection method compared to

228 phenotypic detection among the $S$. aureus isolates $(P$ value $=0.046703)$. However, there

229 was no significant correlation between genotypic and phenotypic detection among the

230 CoNS tested isolates $(P$ value $=0.248213)$.

231 Table 5. Descriptive statistics, results of Fisher's Exact test and Mann-Whitney U test for 232 comparison between ELISA results and detected genes among bacteremic and IE isolates.

\begin{tabular}{ccccc}
\hline Outcome & IE $(\mathrm{n}=15)$ & Bacteremia $(\mathrm{n}=11)$ & $P$-value & Effect size \\
\hline ELISA [Median (Range) & $1.92(0-2.59)$ & $0(0-2.05)$ & 0.085 & $d=0.677$ \\
Detected genes [n (\%)] & & & & \\
Sea & $10(66.7 \%)$ & $5(45.5 \%)$ & 0.426 & $v=0.212$ \\
Seb & $8(53.3 \%)$ & $4(36.4 \%)$ & 0.453 & $v=0.168$ \\
Sed & $0(0 \%)$ & $1(9.1 \%)$ & 0.423 & $v=0.234$ \\
tsst1 & $4(26.7 \%)$ & $0(0 \%)$ & 0.113 & $v=0.365$ \\
$\begin{array}{l}\text { Total number of genes [Median } \\
\text { (Range)] }\end{array}$ & $2(0-2)$ & $1(0-3)$ & 0.139 & $d=0.572$ \\
\hline & & & &
\end{tabular}

We studied correlation between the ELISA results among staphylococcus isolates in association

236 with the respective genes detected. As shown in table 6, isolates with (sea) gene showed

237 statistically significantly higher median ELISA results than isolates without (sea) gene $(P$-value 
$238=0.005$, Effect size $=1.215)$. There was no statistically significant difference between ELISA

239 results in isolates with and without (seb and tsst 1$)$ genes $(P$ value $=0.978$, Effect size $=0.010)$

240 and $(P$ value $=0.940$, Effect size $=0.028)$, respectively. As regards to sed gene, no statistical

241 comparison was performed because there was only one isolate harbored this gene.

242 Table 6. Median, range and results of Mann-Whitney $U$ test for comparison between 243 ELISA results in association with the detected genes.

\begin{tabular}{lcccc}
\hline Gene & Present & Absent & $P$-value & $\begin{array}{c}\text { Effect size } \\
(d)\end{array}$ \\
\hline sea & $2.03(0-2.59)$ & $0(0-2.03)$ & $0.005^{*}$ & 1.215 \\
seb & $0.01(0-2.59)$ & $0.95(0-2.08)$ & 0.978 & 0.010 \\
sed & Only one case & $0.05(0-2.59)$ & Not computed \\
tsst-1 & $0.94(0-2.04)$ & $0.03(0-2.59)$ & 0.940 & 0.028 \\
\hline
\end{tabular}

247 Globally, BSIs are the major cause of infectious disease morbidity and mortality. Recently, the epidemiology of BSIs has been changed, as a result of many factors, for example increasing 249 globalization, emerging of antimicrobial-resistant organisms, changing population demographic 250 and modifications in health care delivery models [27, 28]. It is reported that $S$. aureus is the 251 second most common species causing BSIs [28]. Genetic variation of genes that encodes for SAg 252 production by Staphylococcus spp. may contribute to the occurrence of IE in the course of 253 bacteremia. Therefore, it is important to highlight on the prevalence of SAgs in IE as well as in 254 bacteremic patients.

255 The cornerstones of clinical diagnosis of IE rely on integration of clinical, microbiological, 256 echocardiography and laboratory findings; these are underlined in the modified Duke criteria for 
257 diagnosis of IE. Several studies have reported the high sensitivity of the Duke criteria in the 258 diagnosis of IE [29]. In the present study, the mean age of our patients was $33 \pm 11.3$ years. The 259 majority of patients were male representing $83 \%$ and the remaining $17 \%$ were female patients. 260 Similar findings were previously reported $[30,5,12]$. The higher incidence of IE among the 261 young, male patients is attributed to the predominance of the injection drug users (IDUs), which 262 is considered a problem related mainly to the young males in our Egyptian society [31]. The study revealed $75 \%$ of the IDUs were HCV positive. These results were in agreement with those reported by a study conducted on IE patients who were intravenous (I.V) addicts; they reported that $86 \%$ of the patients were HCV positive [32]. Our findings were in accordance with results reported by a study conducted by Ghosh et al., in which $91 \%$ of the patients had fever as the

267 most prevalent symptom [33]. However, absence of fever cannot rule out the diagnosis of IE especially in patients with important clinical features. All our IE patients had native valve IE,

269 this for the reason that postoperative prosthetic valve patients followed a strict follow-up with 270 adequate medical care, so the prevalence of IE among these patients decreased significantly [33]. 271 Among the IDUs, the tricuspid valve was the most commonly affected valve (66.7\%). Similar

272 finding was observed in a previous study [34].

273 The results of our study revealed that the higher prevalence was for the Gram positive isolates $274(69.4 \%)$ causing BSIs compared to the Gram negative isolates (25.8\%). Among the recovered 275 Gram positive isolates, the highest prevalence was for the CoNS (50.8\%), followed by S. aureus $276(44.1 \%)$ and the least prevalence was for the Streptococcus spp. (5\%). The epidemiology of BSIs 277 towards Gram positive pathogens could be due to the increase in risk factors in the populations 278 including older age, diabetes, end-stage renal disease, intra-cardiac devices, increased use of 279 invasive procedures, I.V drug use as well as frequent insertion of central venous catheters. All 
280 these mentioned patient risk factors may lead to the development of complicated BSIs with MRSA as well as CoNS [35, 36].

282 When assessing the susceptibility of $S$. aureus to different antimicrobial agents, our results revealed that MRSA was responsible for most S. aureus bacteremia (92.3\%) and also cefoxitin resistance among CoNS was highly noticed with percentage 93.3\%. Our results were in agreement with the results of several studies conducted in Egypt reporting the high frequency of MRSA among $S$. aureus isolates with percentages $40 \%$ and $88 \%$, respectively [37, 38]. As for

287 the susceptibility of the isolates to vancomycin, $92.3 \%$ of the $S$. aureus isolates were sensitive and $93.3 \%$ of the CoNS were also sensitive to vancomycin. Accordingly, vancomycin remains the drug of choice, and the most appropriate and commonly used treatment for Staphylococcal BSI's. In particular, vancomycin is endorsed by the Infectious Diseases Society of America (IDSA) MRSA guidelines as the main treatment choice for MRSA bacteremia [39].

292 IE usually results from infection by Gram-positive bacteria and infrequently from Gram-negative 293 bacteria. This may be due to that the Gram positive bacteria have capability to adhere and inhabit 294 damaged valves [40]. In addition Gram positive bacteria are armed with numerous superficial 295 adhesins that arbitrate attachment to extracellular host matrix proteins [41]. S. aureus, 296 Streptococcus spp., and enterococci are the most common IE pathogens which responsible for 297 more than $80 \%$ of IE cases [42, 43]. Historically, Streptococcus species have been the main 298 causative microorganisms of IE. However, recently, other pathogens have gained importance. $S$. 299 aureus has become the predominant causative organism in the world, in both hospital settings as 300 well as the community, followed by CoNS [36, 1]. Accordingly, S. aureus was the most 301 commonly isolated pathogen (52.6\%), followed by CoNS $(26.3 \%)$. Same finding were reported 
302 in a study conducted by Fatima et al., where $S$. aureus was found to be the predominant organism

303 causing IE (38\%) [37].

304 To date, several SAgs have been identified and globally, SAg genes have been found in over $30570 \%$ of $S$. aureus isolates $[44,45]$. Various immunological and molecular methods have been 306 developed for the phenotypic and genotypic detection of SAgs. The prevalence of five SEs 307 encoding genes (A-E) as well as the tsst-1 was investigated by PCR amplification. The results revealed that among the total Staphylococcal isolates, $57.9 \%$ carried two or more genes of the assessed SAgs, while $42 \%$ of the isolates had only one gene. From the 15 isolates recovered from IE patients, $93 \%$ of the isolates had at least one SAg gene and $53 \%$ had two SAg genes. In addition, among S. aureus isolates there were $80 \%$ of the isolates had at least one SAg gene and these were in accordance with those reported in several studies, where they found that $70-90 \%$ of the isolates had one SAg gene [44, 46]. However, lower percentage was reported by Chung et al.,

314 where out of the 124 isolates, $63 \mathrm{~S}$. aureus isolates (50.8\%) had at least one SAg gene [47].

315 Among the S. aureus isolates SAg genes, sea was the most commonly found gene followed by

316 the seb gene, tsst-1 and the least prevalence was for the sed. The genes coding for enterotoxins

$317 \mathrm{C} 1$ and E were not found among the tested isolates. Our results were in accordance with other 318 reports $[48,49]$. They found the highest frequency for sea gene, followed by the seb gene and 319 sed genes. In contrast to our study, Nhan et al., found that sec and seb genes were the most 320 prevalent toxin genes in their study [50].

321 The molecular detection of SAg was found to be more sensitive and efficient than the ELISA 322 test, since the results of the PCR amplification revealed that 20 out of the 26 isolates were 323 positive for SAg genes. However, only 12 isolates were positive for enterotoxin production. This 324 could be due to the low level production of enterotoxins and TSST-1 by some isolates, which are 
not detected by VIDAS ELISA. Also, it is unable to differentiate between active and inactive SEA [51]. Another possible explanation is that expression of SAgs genes is more prominent in vivo than in in vitro culture methods.

In spite of this, the question remains as to whether IE Staphylococcus isolates differ from non-IE bacteremia isolates. Our results showed no significant difference between Staphylococcal IE and bacteremia isolates with respect to both phenotypic and genotypic detection of the most commonly found SAgs. Our data rule out the possibility of a single specific SAg responsible for the occurrence of IE in the course of Staphylococcal bacteremia. Our results were in accordance with Bouchiat et al., and Gallardo-García et al., where they found no association between any SAg and IE [48, 52]. On the other hand, in 2014, Chung et al. analyzed a series of 124 S. aureus isolates in IE, and found a significant correlation between SAgs and IE [47]. Moreover, in 2012, Tristan et al. found that the genes encoding toxic shock syndrome toxin- 1 and staphylococcal enterotoxin A, the two major SAgs from $S$. aureus, were enormously widespread in IE isolates from the USA $93.9 \%$ and $64.9 \%$, respectively [46]. Accordingly, they suggested that IE isolates carry specific virulence factors that differ from those found in isolates tested from patients suffering other infections [46].

\section{Conclusion}

In conclusion, there was a statistically significant difference between phenotypic and the genotypic detection methods among the Staphylococcal tested isolates. On the other hand, our study revealed that no significant difference has been found between Staphylococcal IE and bacteremia isolates regarding both phenotypic and genotypic detection of the most commonly SAgs. Accordingly, all Staphylococcal bacteremic patients are suspected to have IE. It is 
347 important to note that one limitation of the study was unable to establish SAg gene expression in

348 vitro. However, detection of SAgs gene expression will be made in our future research.

FUNDING INFORMATION

This work received no specific grant from any funding agency.

\section{ACKNOWLEDGMENT}

352 The research team expresses sincere gratitude to Dr Zeinab Abdelsalam Fahmy, Professor of 353 Cardiology, Faculty of Medicine, Ain Shams University for providing us with the diagnosis of 354 the IE cases. We express also our gratitude to the Microbiology Laboratory, El-Demerdash 355 hospital Ain Shams University and Ain Shams University Specialized hospital, Cairo, Egypt for 356 providing us with the clinical isolates recovered from blood specimens. Special thanks are to Dr.

357 Al Baraa El Said for analyzing the data statistically.

There is no conflict of interest.

\section{References}

There is no conflict of interest.

\section{References}

1. Boswihi SS, Udo EE. Methicillin-resistant Staphylococcus aureus: An update on the epidemiology, treatment options and infection control. Current Medicine Research and Practice. 2018 Jan 1;8(1):18-24. https://doi.org/10.1016/j.cmrp.2018.01.001 
bacteraemia-associated mortality. Nature microbiology. 2017 Oct;2(10):1381-

3. Asgeirsson H, Thalme A, Weiland O. Staphylococcus aureus bacteraemia and endocarditis-epidemiology and outcome: a review. Infectious Diseases. 2018 Mar 4;50(3):175-92. https://doi.org/10.1080/23744235.2017.1392039

4. Rali AS, Al-Kofahi M, Patel N, Wiele B, Shah Z, Nath J. The Full Spectrum of Infective Endocarditis: Case Report and Review. Case reports in cardiology. 2019;2019. https://doi.org/10.1155/2019/7257401

5. Choucair J. Infectious causes of vasculitis. Updates in the diagnosis and treatment of vasculitis. 2013 Feb 20.https://www.intechopen.com/books/updates-in-the-diagnosis-and$\underline{\text { treatment-of-vasculitis/infectious-causes-of-vasculitis }}$

6. Spaulding, AR. "Secreted virulence factors in lethal illness due to Staphylococcus aureus." PhD (Doctor of Philosophy) thesis, University of Iowa, 2013. https://doi.org/10.17077/etd.dx8depdd. https://ir.uiowa.edu/etd/4760/ Staphylococcal and streptococcal superantigen exotoxins. Clinical microbiology reviews. 2013 Jul 1;26(3):422-47. DOI: 10.1128/CMR.00104-12

8. Kim AI, Adal KA, Schmitt SK. Staphylococcus aureus bacteremia: using echocardiography to guide length of therapy. Cleveland Clinic journal of medicine. 2003 Jun 1;70(6):517-34. DOI: $\underline{10.3949 / \operatorname{ccjm} .70 .6 .517}$ infections: epidemiology, pathophysiology, clinical manifestations, and management. Clinical microbiology reviews. 2015 Jul 1;28(3):603-61.DOI: 10.1128/CMR.00134-14 
10. Tornos P, Gonzalez-Alujas T, Thuny F, Habib G. Infective endocarditis: the European viewpoint. Current problems in cardiology. 2011 May 1;36(5):175-222. https://doi.org/10.1016/j.cpcardiol.2011.03.004

11. Cahill TJ, Baddour LM, Habib G, Hoen B, Salaun E, Pettersson GB, Schäfers HJ, Prendergast BD. Challenges in infective endocarditis. Journal of the American College of Cardiology. 2017 Jan 16;69(3):325-44. https://doi.org/10.1016/j.jacc.2016.10.066 M, Zandi H, Firoozabadi AD, Banizi NT, Kahtooie FQ, Banaei M. Evaluation of epidemiological, clinical, and microbiological features of definite infective endocarditis. GMS hygiene and infection control. 2017;12. DOI: $\underline{10.3205 / \mathrm{dgkh000286}}$

14. Grumann D, Nübel U, Bröker BM. Staphylococcus aureus toxins-their functions and genetics. Infection, Genetics and Evolution. 2014 Jan 1;21:583-92. https://doi.org/10.1016/j.meegid.2013.03.013 aureus and Staphylococcus argenteus isolates harboring Panton-Valentine leukocidin, enterotoxins, and TSST-1 genes from food handlers in Myanmar. Toxins. 2017 Aug;9(8):241. https://doi.org/10.3390/toxins9080241

16. Prindeze NJ, Amundsen BM, Pavlovich AR, Paul DW, Carney BC, Moffatt LT, Shupp JW. Staphylococcal superantigens and toxins are detectable in the serum of adult burn 
patients. Diagnostic microbiology and infectious disease. 2014 Jul 1;79(3):303-7. https://doi.org/10.1016/j.diagmicrobio.2014.01.024 staphylococcal food poisoning. Frontiers in microbiology. 2018 Mar 13;9:436. https://doi.org/10.3389/fmicb.2018.00436

18. Saeed K, Bal A, Gould I, David MZ, Dryden M, Giannitsioti E, Hijazi K, Meisner JA, Esposito S, Scaglione F, Tattevin P. An update on Staphylococcus aureus infective endocarditis from the International Society of Antimicrobial Chemotherapy (ISAC). International journal of antimicrobial agents. 2019 . https://doi.org/10.1016/j.ijantimicag.2018.09.014 population structure of Staphylococcus aureus from bacteremia in China from 2013 to 2016: ST239-030-MRSA replaced by ST59-t437. Frontiers in microbiology. 2018 Feb 27;9:332. https://doi.org/10.3389/fmicb.2018.00332 endocarditis: utilization of specific echocardiographic findings. The American journal of criteria proposed by the Duke Endocarditis Service to permit improved diagnosis of Q fever endocarditis. The American journal of medicine. 1996 Jun 1;100(6):629-33. https://doi.org/10.1016/S0002-9343(96)00040-X 

Proposed modifications to the Duke criteria for the diagnosis of infective endocarditis. Clinical infectious diseases. 2000 Apr 1;30(4):633-8.. https://doi.org/10.1086/313753

23. Holt JG, Krieg NR, Sneath PH, Staley JT, Williams ST. Bergey's manual of determinative bacteriology. 9th. Baltimor: William \& Wilkins. 1994.

24. CLSI. Performance Standards for Antimicrobial Susceptibility Testing. Clinical and Laboratory Standards Institute, USA, 2016. ISBN: 1-56238-924-6 Staphylococcus aureus enterotoxins, exfoliative toxins, toxic shock syndrome toxin 1, and methicillin resistance. Journal of clinical microbiology. 2000 Mar 1;38(3):1032-5. PMID:10698991 PMCID:PMC86330

28. Laupland KB, Church DL. Population-based epidemiology and microbiology of

26. Sambrook J, Russel DW. Molecular cloning a laboratory manual. Vol. 3, pp. of organisms causing bloodstream infection in critically ill patients. Journal of clinical community-onset bloodstream infections. Clinical microbiology reviews. 2014 Oct 1;27(4):647-64. https://doi.org/10.1128/CMR.00002-14

29. Topan A, Carstina D, Slavcovici A, Rancea R, Capalneanu R, Lupse M. Assesment of the Duke criteria for the diagnosis of infective endocarditis after twenty-years. An analysis of 241 cases. Clujul Medical. 2015;88(3):321.DOI: $\underline{\text { 10.15386/cjmed-469 }}$ 
30. Assiri AS. Clinical and microbiological profiles of infective endocarditis in a tertiary hospital in Aseer region, Saudi Arabia. Journal of the Saudi Heart Association. 2011 Oct 1;23(4):207-11. https://doi.org/10.1016/j.jsha.2011.04.002

31. Galal H, Rifaei O, Rahman MA, El-Sayed H. Prevalence and characteristics of tricuspid valve endocarditis among patients presented to Ain Shams Hospital echocardiography lab; one year study. The Egyptian Heart Journal. 2018 Jun 1;70(2):59-63. https://doi.org/10.1016/j.ehj.2017.12.009 surgery for infective endocarditis in patients with intravenous drug use. Interactive cardiovascular and thoracic surgery. 2016 May 1;22(5):633-40.DOI: $\underline{10.1093 / \text { icvts/ivv397 }}$ microbiological, and Echocardiographic profile of patients of infective endocarditis. International scholarly research notices. 2014;2014. http://dx.doi.org/10.1155/2014/340601

34. Vallejo FA. Epidemiology of Infective Endocarditis. Contemporary Challenges in Endocarditis. 2016 ;9:35. https://www.intechopen.com/books/contemporary-challenges-inendocarditis/epidemiology-of-infective-endocarditis bloodstream infections caused by methicillin-resistant Staphylococcus aureus at a tertiary care hospital in New York. American journal of infection control. 2016 Jan 1;44(1):41-6. https://doi.org/10.1016/j.ajic.2015.08.005 
477

478

479

480

481

482

483

484

485

486

487

488

489

490

491

492

493

494

495

496

497

498

499

36. Fatima S, Dao B, Jameel A, Sharma K, Strogatz D, Scribani M, Rammohan HR. Epidemiology of infective endocarditis in rural upstate New York, 2011-2016. Journal of clinical medicine research. 2017 Sep;9(9):754. https://doi.org/10.14740/jocmr3131w

37. Mohammed EY, Abdel-Rhman SH, Barwa R, El-Sokkary MA. Studies on enterotoxins and antimicrobial resistance in Staphylococcus aureus isolated from various sources. $\begin{array}{lllll}\text { Advances } & \text { in } \quad \text { Microbiology. } & 2016 \quad \text { Apr } & \text { (4):263- }\end{array}$ 75.http://dx.doi.org/10.4236/aim.2016.64026

38. Elshabrawy WO, Zaki ME, Kamel MF. Genetic and phenotypic study of methicillinresistant Staphylococcus aureus among patients and health care workers in Mansoura University Hospital, Egypt. Iranian journal of microbiology. 2017 Apr;9(2):82. PMID: 29213999

39. Truong J, Veillette JJ, Forland SC. Outcomes of vancomycin plus a $\beta$-lactam versus vancomycin only for treatment of methicillin-resistant Staphylococcus aureus bacteremia. Antimicrobial agents and chemotherapy. 2018 Feb 1;62(2):e01554-17.

DOI: $\underline{10.1128 / \mathrm{AAC} .01554-17}$

40. Moreillon P, Que YA, Bayer AS. Pathogenesis of streptococcal and staphylococcal endocarditis. Infectious Disease Clinics. 2002 Jun 1;16(2):297-

\section{8.https://doi.org/10.1016/S0891-5520(01)00009-5}

41. Patti JM, Allen BL, McGavin MJ, Höök M. MSCRAMM-mediated adherence of microorganisms to host tissues. Annual Reviews in Microbiology. 1994 Oct;48(1):585617.DOI: $10.1146 /$ annurev.mi.48.100194.003101

42. Murdoch DR, Corey GR, Hoen B, Miró JM, Fowler VG, Bayer AS, Karchmer AW, Olaison L, Pappas PA, Moreillon P, Chambers ST. Clinical presentation, etiology, and 
outcome of infective endocarditis in the 21st century: the International Collaboration on Endocarditis-Prospective Cohort Study. Archives of internal medicine. 2009 Mar 9;169(5):463-73.DOI: 10.1001/archinternmed.2008.603

43. Benito N, Miró JM, de Lazzari E, Cabell CH, Del Río A, Altclas J, Commerford P, Delahaye F, Dragulescu S, Giamarellou H, Habib G. Health care-associated native valve endocarditis: importance of non-nosocomial acquisition. Annals of internal medicine. 2009 May 5;150(9):586-94.DOI: 10.7326/0003-4819-150-9-200905050-00004

44. Varshney AK, Mediavilla JR, Robiou N, Guh A, Wang X, Gialanella P, Levi MH, Kreiswirth BN, Fries BC. Diverse enterotoxin gene profiles among clonal complexes of Staphylococcus aureus isolates from the Bronx, New York. Appl. Environ. Microbiol.. 2009 Nov 1;75(21):6839-49. DOI: 10.1128/AEM.00272-09

45. Zhang DF, Yang XY, Zhang J, Qin X, Huang X, Cui Y, Zhou M, Shi C, French NP, Shi $\mathrm{X}$. Identification and characterization of two novel superantigens among Staphylococcus aureus complex. International Journal of Medical Microbiology. 2018 Jun 1;308(4):43846. https://doi.org/10.1016/j.ijmm.2018.03.002

46. Tristan A, Rasigade JP, Ruizendaal E, Laurent F, Bes M, Meugnier H, Lina G, Etienne J, Celard M, Tattevin P, Monecke S. Rise of CC398 lineage of Staphylococcus aureus among infective endocarditis isolates revealed by two consecutive population-based studies in France. PLoS One. 2012;7(12).https://doi.org/10.1371/journal.pone.0051172

47. Chung JW, Karau MJ, Greenwood-Quaintance KE, Ballard AD, Tilahun A, Khaleghi SR, David CS, Patel R, Rajagopalan G. Superantigen profiling of Staphylococcus aureus infective endocarditis isolates. Diagnostic microbiology and infectious disease. 2014 Jun 1;79(2):119-24.https://doi.org/10.1016/j.diagmicrobio.2014.03.009 
48. Bouchiat C, Moreau K, Devillard S, Rasigade JP, Mosnier A, Geissmann T, Bes M, Tristan A, Lina G, Laurent F, Piroth L. Staphylococcus aureus infective endocarditis versus bacteremia strains: subtle genetic differences at stake. Infection, Genetics and Evolution. 2015 Dec 1;36:524-30. https://doi.org/10.1016/j.meegid.2015.08.029

49. Yu F, Li T, Huang X, Xie J, Xu Y, Tu J, Qin Z, Parsons C, Wang J, Hu L, Wang L. Virulence gene profiling and molecular characterization of hospital-acquired Staphylococcus aureus isolates associated with bloodstream infection. Diagnostic microbiology and infectious disease. 2012 Dec 1;74(4):363-8. https://doi.org/10.1016/j.diagmicrobio.2012.08.015

50. Nhan TX, Leclercq R, Cattoir V. Prevalence of toxin genes in consecutive clinical isolates of Staphylococcus aureus and clinical impact. European Journal of Clinical Microbiology \& Infectious Diseases. 2011 Jun 1;30(6):719-25. https://doi.org/10.1007/s10096-010$\underline{1143-4}$

51. Rasooly R, Do P, He X, Hernlem B. Alternative to Animal Use for Detecting Biologically Active Staphylococcal Enterotoxin Type A. Toxins. 2018 Dec;10(12):540. https://doi.org/10.3390/toxins10120540

52. Gallardo-Garcia MM, Sanchez-Espin G, Ivanova-Georgieva R, Ruiz-Morales J, Rodriguez-Bailon I, Gonzalez VV, García-López MV. Relationship between pathogenic, clinical, and virulence factors of Staphylococcus aureus in infective endocarditis versus uncomplicated bacteremia: a case-control study. European Journal of Clinical Microbiology \& Infectious Diseases. 2016 May 1;35(5):821-8. https://doi.org/10.1007/s10096-016-2603-2 